\title{
Efficiency Analysis of Electricity, Thermal Power Production and Supply Industries in China
}

\author{
Xuefeng Jiang \\ Department of Economics, Jinan University, Guangzhou, China \\ Email: 13129363493@163.com
}

How to cite this paper: Jiang, X.F. (2019) Efficiency Analysis of Electricity, Thermal Power Production and Supply Industries in China. American Journal of Industrial and Business Management, 9, 950-973. https://doi.org/10.4236/ajibm.2019.94065

Received: April 3, 2019

Accepted: April 23, 2019

Published: April 26, 2019

Copyright $\odot 2019$ by author(s) and Scientific Research Publishing Inc. This work is licensed under the Creative Commons Attribution International License (CC BY 4.0).

http://creativecommons.org/licenses/by/4.0/

\section{(c) (i) Open Access}

\begin{abstract}
In this paper, the input-oriented distance function is applied to the efficiency analysis of China's electricity, thermal power production and supply industries. Due to the obvious gap between China's east, central and west, we use the metafrontier method to divide the data into three parts according to east, central and west. On the basis of the previous research, this paper makes some innovations in the estimation method, that is, using the two-stage linear programming method to estimate the common boundary input distance function. The results show that the technical efficiency of the eastern, central and western regions is significantly different, which is mainly reflected in that the technical efficiency of the eastern region is higher than that of the central and western regions, and the efficiency gap between the three regions shows no signs of narrowing during the "eleventh five-year plan" and "twelfth five-year plan". Therefore, the electricity, thermal power production and supply industries in central and western China still need to change the development mode and improve the development quality.
\end{abstract}

\section{Keywords}

Input Distance Function, Metafrontier, Efficiency, Two-Stage Linear Programming

\section{Introduction}

Electricity, thermal power production and supply industry is the basic pillar industry for national economic development. Specifically, the industry that we will study includes the electricity industry and thermal production and supply industry. Electric power is the power of modern economic development. It provides energy supply and power support for the development of various indus- 
tries in the national economy. Industrial production and people's daily life are inseparable from electric power. The power industry maintains a high correlation with the macro-economy, and the growth rate of power production and power consumption changes with the change of GDP growth rate. Industrial production and people's daily life cannot be separated from the electric energy and heat energy provided by the industry. According to China Statistical Yearbook, from 2001 to 2013, driven by the rapid development of national economy and the electricity demand brought by industrialization and urbanization, the national electricity demand maintained an average annual rate of $11.22 \%$. The thermal power production and supply industry refers to the activities of using coal, oil, gas and other energy resources to produce steam and hot water through boilers and other devices, or outsourcing steam and hot water for supply and sales, maintenance and management of heating facilities. It is a key industry supported by the state in the field of capital construction. The thermal production and supply industry is extremely important for areas needing heating in winter, and is also deeply associated with basic industries such as power, construction and coal. China's "twelfth five-year" plan which is an important economic development plan involves the industry's development and reform, such as "energy twelfth five-year planning" indicating the developing direction of the thermal power cogeneration, "building energy saving special planning during twelfth five-year" put forward to deepen the reform of the heating system, implementation of heating metering, promoting energy-saving renovation of existing buildings in northern heating metering and energy-saving ability of 27 million tons of standard coal, the "plan for heat metering heating in the north area for existing residential buildings during twelfth five-year" pointing out that to improve the 7 million urban residents heating and living conditions, we should strive to complete the old residential energy saving transformation of 1.2 billion square meters in the northern heating area by 2020 . To sum up, the electricity, thermal power production and supply industries are closely related to the development of the national economy, so it is of great research value.

With the rapid development of China's economy, the problems existing in the production and supply of electricity and heat are becoming more and more prominent. The 2010 statistical report on national economic and social development lists it as an energy-intensive industry along with the manufacturing of chemical raw materials and chemical products, non-metallic mineral products, ferrous metal smelting and rolling industry, non-ferrous metal smelting and rolling industry, petroleum processing and coking, and nuclear fuel processing industry. "High energy consumption, high pollution, high capacity" is a typical characteristic of electricity, thermal power production and supply industry. As the second largest economy, China's carbon emissions in economic activities play a crucial role in global energy conservation and emission reduction. Over the past 30 years of reform and opening-up, China's economy has achieved rapid development. However, the rapid economic growth is bound to require a large amount of energy input, which brings huge environmental pollution costs. Chi- 
na has long been a major energy consumer. And fossil fuels, especially coal, account for a large proportion of China's energy mix. In recent years, although the Chinese government has vigorously advocated the construction of "low-carbon economy", the adjustment of energy structure still has a long way to go. In 2016, for example, coal still accounted for 61.83 percent of China's energy mix, compared with 6.2 percent for natural gas, 2.82 percent for renewable energy and 8.62 percent for hydropower, according to the world energy statistics yearbook 2017. In the United States during the same period, coal accounted for only $15.77 \%$ and natural gas $31.52 \%$. This is also closely related to China's resource endowment of "rich coal, poor oil and little gas". The energy structure of the electricity, thermal power production industry reflects the characteristics of China's energy structure. The following table is compiled according to China statistical yearbook, which shows the proportion of each type of power generation capacity in China from 2006 to 2015. From this, we can clearly see that the proportion of thermal power in the "eleventh five-year plan" and "twelfth five-year plan" period, although showing a downward trend year by year, but still occupies the dominant position. The production and industry of power and heat are still dominated by thermal power to provide kinetic energy for the development of national economy, which indicates the leading position of coal in the production input of this industry.

Table 1 shows that China's energy structure is coal dependent. Such characteristics of the energy structure make China's carbon emissions increase year by year. As early as 2007, China surpassed the United States as the world's largest carbon dioxide emitter (Lee and Zhang [1]). Large increases in carbon emissions cause temperatures to rise, leading to water shortages, droughts and other severe weather. The energy structure dominated by fossil fuels has also caused serious damage to air quality in China. The six high-energy consuming industries discharge most of the carbon dioxide in our country. As one of the high-energy consuming industries, the production of electricity, thermal power production and supply industries uses coal as the main fuel, and is also the main consumption industry of coal energy, so they also emit a lot of carbon dioxide. Figure 1 shows that the amount of carbon dioxide emissions of electricity, thermal production and supply industry during the period of "eleventh five-year plan", "twelfth five-year" has dominated the six energy-intensive industries more than a half of the total emissions (in addition to 2008, this paper argues that 2008

Table 1. The proportion of each type of power generation capacity.

\begin{tabular}{|c|c|c|c|c|c|c|c|c|c|c|}
\hline & 2006 & 2007 & 2008 & 2009 & 2010 & 2011 & 2012 & 2013 & 2014 & 2015 \\
\hline Thermal power & $77.6 \%$ & $77.4 \%$ & $76 \%$ & $74.5 \%$ & $73.4 \%$ & $72.3 \%$ & $71.5 \%$ & $69.2 \%$ & $67.4 \%$ & $65.9 \%$ \\
\hline Hydroelectric & $20.9 \%$ & $20.6 \%$ & $21.8 \%$ & $22.5 \%$ & $22.4 \%$ & $21.9 \%$ & $21.8 \%$ & $22.3 \%$ & $22.2 \%$ & $20.9 \%$ \\
\hline Wind power & $0.3 \%$ & $0.5 \%$ & $1.1 \%$ & $1 \%$ & $1 \%$ & $1.2 \%$ & $1.1 \%$ & $1.2 \%$ & $1.5 \%$ & $1.9 \%$ \\
\hline Solar power & 0 & 0 & 0 & 0 & $0.03 \%$ & $0.2 \%$ & $0.3 \%$ & $1,3 \%$ & $1.8 \%$ & $2.8 \%$ \\
\hline Nuclear power & $1.1 \%$ & $1.3 \%$ & $1.1 \%$ & $1 \%$ & $1.1 \%$ & $1.2 \%$ & $1.1 \%$ & $1.2 \%$ & $1.5 \%$ & $1.8 \%$ \\
\hline
\end{tabular}




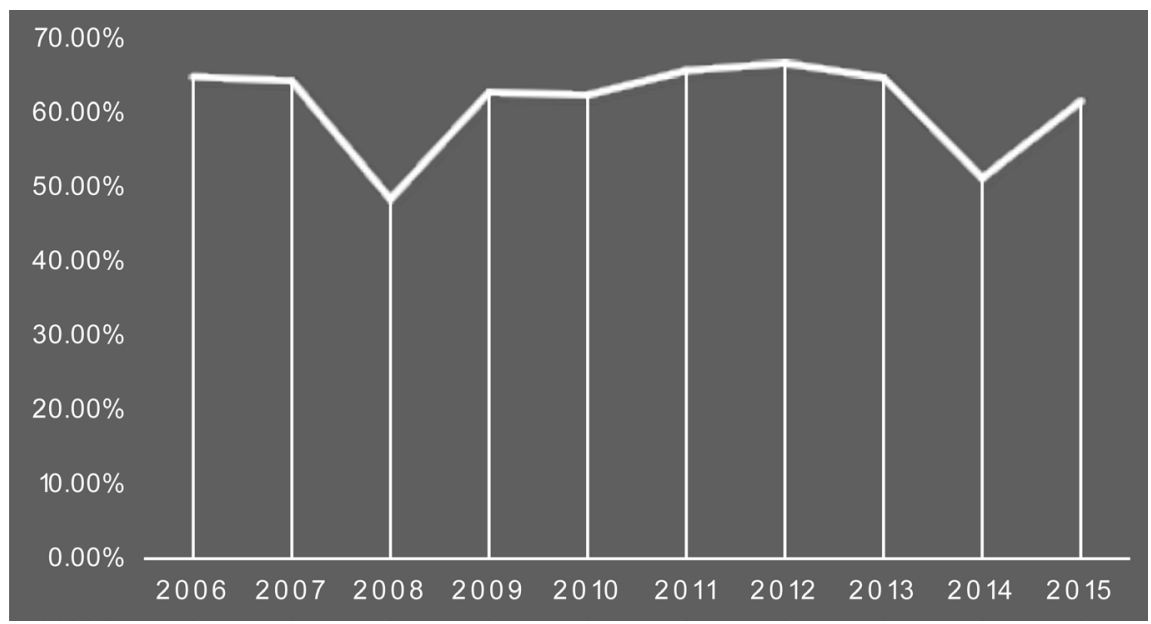

Figure 1. The amount of carbon dioxide emissions of electricity, thermal production and supply industry from 2006 to 2015.

Olympic Games country stepped up to the industry the management of pollutants discharge, slowed in 2008 emissions).

In addition to producing a lot of carbon dioxide, according to the 2009 China environmental statistical annual report, the power industry in this industry also emits a lot of nitrogen oxides and soot, accounting for $64.5 \%$ and $40.8 \%$ of the total national emissions in that year respectively. From this point of view, the pollutants produced by the production and supply industries of power and heat have an extremely important impact on the quality of China's atmospheric environment. The development of this industry is directly related to the improvement of air quality in China.

There are still problems of extensive development and low efficiency in the production and supply of power and heat. Although the power and thermal power production and supply industries have invested a lot of energy, their energy output ratio is lower than that of developed countries, which indicates that the development mode of this industry is not sophisticated enough and the quality is not optimized enough. During the 11th and 12th five-year plans, the total energy consumption of the power and thermal power production and supply industries increased by about $29 \%$. And Denmark, for example, since 1970, Denmark's economy grew by $70 \%$, but energy consumption has remained at the levels of the 1970s, energy efficient utilization and the improvement of the building insulation technology contributed to the high quality development of Denmark, in addition, its reasonable way of heating is also one reason: cogeneration, natural gas and renewable energy provides a Danish domestic three-quarters of heat load demand. Therefore, the development mode of China's electricity, thermal power production and supply industry in the "eleventh five-year", "twelfth five-year" period is relatively extensive, to promote the industry to improve quality and efficiency, eliminate backward capacity, optimize the development mode is crucial. This is not only conducive to the transformation of the industry's development mode, but also related to the healthy and sustainable 
development of the national economy. So it is necessary to analyze the efficiency of electricity, thermal power production and supply industries.

\section{Literature Review}

Distance function is a useful method to measure efficiency and productivity. Many scholars have applied it to different industries or enterprises. It differs from the traditional production function in that it can consider multiple inputs and outputs. In the efficiency analysis of industries (especially the polluting industries), not only the good output but also the bad output should be taken into account, because some industries will produce a large number of pollutants in the production process. If not taken into account, the efficiency analysis will inevitably be biased. The distance function can contain both good and bad outputs for efficiency analysis. It is the advantage that makes the distance function widely used in the field of environmental economics. In essence, the distance function can be regarded as a production function composed of frontier. Specifically, the various production units which are regarded as research subject are facing a potential production frontier, this can also be called production technology boundaries. Input and output combination on the boundary of portfolio is the combination under the optimal condition. If production units are on the production boundary, we may consider the unit of production to be the most efficient, and the allocation of resources is also the most optimal condition. But in reality, the actual input-output combination of most production units is not an efficient combination, in other words, it deviates from the optimal technical boundary. At this time, there is a gap between the actual input-output combination of the inefficient production unit and the optimal input-output combination, and the gap is the inefficiency level of the production unit, namely the estimated value of the distance function, which is also the reason why this method is called the distance function. The distance function is divided into input distance function, output distance function and direction distance function. The input distance function is input-oriented and assumes the same output, so as to calculate the minimum input that can be used to produce the same output. The output distance function is output oriented and measures the maximum output that the same input can produce. The directional distance function constructs a more demanding technology frontier, which requires the increase of good output and the decrease of bad output.

Input distance function measures the efficiency and productivity performance of a production unit from the perspective of input. Many foreign literatures use it to evaluate the efficiency and productivity of enterprises or industries. Shephard [2], Shephard [3] and Färe and Primont [4] laid the theoretical foundation for the generation and development of distance function. Based on the previous theories, Hailu and Veeman [5] estimated the technical efficiency, Mlmquist productivity index and pollutant reduction cost of Canadian pulp and paper industry by using the method of input distance function. At the same time, the 
author used the traditional method to measure the efficiency and productivity of paper industry without considering the bad output. By comparing the two, the authors found that ignoring bad output understates firms' performance, mainly because ignoring bad output ignores firms' investment in cutting emissions. In the same way, Lee [6] evaluated the efficiency performance of 51 thermal power plants in the United States from 1977 to 1986, the shadow price of sulfur dioxide and the elasticity of substitution between sulfur dioxide and capital. The results show that the average efficiency of these thermal power plants is 0.945 . Zhou et al. [7] adjusted the input distance function to keep the output, capital and labor unchanged, and then estimated the energy efficiency. The adjusted input distance function is called the energy distance function. The energy distance function is used to estimate the energy efficiency index of OECD countries based on SFA and non-parametric DEA. Lee and Zhang [1] applied the input distance function to 30 manufacturing industries in China for the first time, and evaluated the technical efficiency of these industries. The results showed that seven industries were technically efficient, and the technical efficiency of printing industry and copy industry of record media was only 0.26 . Das and Kumbhakar [8], Das and Kumbhakar [9] studied the efficiency performance of Indian Banks based on the input distance function. Ma and Hailu [10] from 2001 to 2010, Chinese provincial data is used to estimate cost for the provinces of carbon emissions, this article will be three different distance functions are applied to the article has carried on the comparison and analysis, found that the output distance function similar to the input distance function estimation results, direction distance function estimation results floating is bigger.

The output distance function measures the potential output capacity of an enterprise, so many scholars apply it to efficiency analysis. Färe [11] first developed the output distance function using Shephard [3] duality theory and applied the method to estimate the shadow price of pollutants. Färe [12] then uses this method to calculate the shadow price of pollutants in the paper industry in Wisconsin. Coggins and Swinton [13] estimated the technical efficiency and emission reduction cost of 14 thermal power enterprises in Wisconsin by using the output distance function. The average technical efficiency of these 14 thermal power plants was about 0.95 , indicating that their production efficiency had $5 \%$ room for improvement. Swinton [14] extended the research scope of the 1996 paper to include thermal power plants in Illinois, Minnesota and Wisconsin, and used the same method to measure the efficiency. The results showed that the technical efficiency of thermal power plants in these three places was 0.92, 0.92 and 0.85 , respectively. Swinton [15] studied the technical efficiency status of seven thermal power plants in Florida between 1990 and 1998 and the cost saving potential of the sulfur dioxide emission trading market. Newman and Matthews [16] constructed the total factor productivity index based on the output distance function, which was decomposed into technical change, efficiency change and scale efficiency change. Then the productivity index is used to ana- 
lyze the productivity changes of Irish dairy farms from 1984 to 2000 . The result is that productivity on Ireland's dairy farms is growing by $1.2 \%$ a year. Newman and Matthews [17] used the same method to compare the productivity of the four agricultural systems-sheep, cow pasture, farmland and cattle raising. Among them, the productivity of the sheep system increased the most, while that of the cattle raising system decreased. Feng and Serletis [18] studied the total factor productivity of the large US Banks (assets at more than \$one hundred million) from 2000 to 2005, and found that the average annual growth rate of these banks' total factor productivity during this period is $1.98 \%$, but the total factor productivity growth rate showed a trend of decline, this is mainly due to a slowdown in the technical improvement. Areal et al. [19] estimated the efficiency index of 215 dairy farms in England and wales based on the proportion of permanent pasture in total agricultural land as an environmental output based on the output distance function, and the results showed that the technical efficiency ranking of dairy farms changed after the addition of environmental output. Assaf and Agbola [20] calculate the efficiency value of accommodation industry in Australia from 1998 to 2009, and found that different regions and different types of accommodation departments have different efficiency scores, and considered that the degree of internationalization of regions, the proportion of large companies in the departments and the regional economic conditions were the main factors affecting the efficiency value.

The directional distance function is mainly applied to polluting industries, because it assumes that good output increases, but at the same time bad output decreases, which is an ideal development model for polluting industries. A large number of scholars take this as a standard to measure the efficiency and productivity of enterprises. Chung et al. [21] introduced the directional distance function when he studied the productivity of Swedish paper industry. He thought that the directional distance function was suitable for studying enterprises producing both good output and bad output. Färe et al. [22] expatiated on the theoretical properties of the directional distance function and applies it to the efficiency measurement of 209 thermal power enterprises in the United States. McMullen and Noh [23] measured the efficiency value of the transportation system by using the direction distance function under the condition of considering the exhaust emissions (bad output) of the US transportation system, and found that when considering the bad output, the performance of more transportation sectors was efficient, and the efficiency of the public sector was lower than that of the private sector. Watanabe and Tanaka [24] used the data from provincial level industrial analysis of the efficiency of various provinces in China based on the direction distance function in measuring the efficiency value when the author got the two situations, i.e. consider bad output and does not consider a bad output. They found five coastal provinces in the two cases are the most efficient, but the Shandong, Sichuan, Hebei three provinces under the condition of without considering the bad output efficiency value will be overvalued, at the 
same time, the article results also indicated that a province's industrial structure had a significant impact on the efficiency of its value. Murty et al. [25] used direction distance function to estimate the technical efficiency of India's five power and pollutant emission reduction cost. It is found that the average technical efficiency of thermal power plants was 0.06 , indicating that power has the potential to improve the level of technology with $6 \%$ increase for good output and $6 \%$ reduction in pollution emissions at the same time, achieving output increased at the same time, but also improve environmental quality. Macpherson et al. [26] improved the traditional directional distance function in the calculation of the environmental performance of the United States region, and added more stringent requirements on the basis of the previous one, that is, the increase of good output and the decrease of bad output should be accompanied by the decrease of input. According to this theory, the author calculated the environmental technology efficiency of 134 river basins on the east coast of the United States, and found that the evaluation of technology efficiency would be affected by the consideration of socio-economic factors, such as per capita national income and population density. Yuan et al. [27] studied the environmental efficiency of industrial sector in 284 cities of China in 2003 and 2009, the average environmental technology efficiency of China's urban industrial sector is 0.947 , of which the east has the highest efficiency value, followed in the west and in the middle of the lowest. The article further analyzed the factors that influence efficiency of environmental technology, and results showed that the U-shaped relationship is presented between income level and the technical efficiency. Foreign capital has played a positive role in the technical efficiency of ascension for industrial sector, and denied the "pollution haven hypothesis". Wang et al. [28] analyzed the energy efficiency and productivity of 28 provinces in China (excluding Hainan and Tibet) in the "eleventh five-year plan" by using the directional distance function, and compared three situations: energy conservation; energy conservation and emission reduction; energy conservation, emissions reduction and economic growth. The study found that China's energy efficiency and productivity were very different in the three scenarios. In the third scenario, China's energy efficiency during the 11 th five-year plan period was 0.6306 , while the average annual growth rate of energy productivity was only $0.27 \%$. Xie et al. [29] estimated the technical efficiency of each province, shadow price and the elasticity of substitution of the $\mathrm{SO}_{2}$ with industrial sector data of China's 30 provinces from 1998 to 2011 under the condition of considering the $\mathrm{SO}_{2}$ emissions. Results showed that during the period of study, the technical inefficiency of China's industrial sector showed U-shaped curve change trend. And the turning point appeared in 2005. A positive elasticity of substitution between good and bad output suggests that a reduction in $\mathrm{SO}_{2}$ emissions is possible while boosting economic growth.

The distance function shown above has a commonality that only one frontier is constructed. To be specific, it assumes that there is no heterogeneity among all 
production units, and they share a common technological frontier. But this assumption is obviously not in conformity with the actual situation. For example, when we study the efficiency of the agricultural sector in developed and developing countries, the common technological frontier is wrong because domestic environment, policy, science and technology level are very different between developed and developing countries. So the analysis under the same technological frontier is bound to make biased efficiency evaluation, then it is necessary for us that is similar in nature to include production units as a group. By this way, each group has its own specific the technological frontier in the group, and then we must structure a potential frontier to envelope group technological frontier. We call this potential frontier common boundary, namely metafrontier. Hayami [30], Hayami and Ruttan [31] laid the foundation for the common boundary theory. Battese and Rao [32] introduced the concept of common boundary based on stochastic frontier, and on this basis, deduced the formula of technical efficiency and technical gap, laying a foundation for future empirical analysis. Rao et al. [33] combined the output distance function and input distance function with the common boundary to calculate the agricultural technology efficiency and technology gap of 97 countries (compared with the metafrontier). In this empirical study, the author divided these countries into four groups, namely Africa, America, Asia and Europe. Battese et al. [34] used the metafrontier production function to measure the technical efficiency of India's garment industry in new Asia from 1990 to 1995 and the technological gap relative to the potential technological frontier. On the basis of Rao et al. [33], O'donnell et al. [35] considered the issue of multiple outputs. Huang et al. [36] used the same method to study the cost efficiency of Taiwan's power distribution industry. According to Huang et al. [36], the traditional cost efficiency analysis failed to take into account the heterogeneity of each power distribution enterprise, resulting in overestimation. Chen [37] combined the metafrontier and input distance function to calculate the technical efficiency, technology gap, scale efficiency and productivity of Taiwan's banking industry. This paper divided the Banks studied into public ownership and private ownership, and found that the productivity index of private Banks would be overestimated without considering the risk investment. Huang et al. [38] adopted a new metafrontier estimation method. In this paper, SFA estimation method is adopted in the estimation of intra-group technology frontier and common technology frontier (i.e. metafrontier), which is different from Huang [36] and Chen [37]. Huang et al. [39] combined the directional distance function with the common boundary to calculate the efficiency of Banks in countries in central and Eastern Europe. Zhang and Wang [40] proposed the Luenberg productivity index based on metafrontier and applied it to the productivity analysis of South Korean thermal power plants. Du et al. [41] used the metafrontier to calculate the technical efficiency, technical gap and shadow price of sulfur dioxide of China's thermal power plants. In this paper, parametric linear programming method was used to estimate the technological frontier within the group and metafrontier. 
In this paper, the method of input distance function is used to estimate the efficiency and productivity of electricity, thermal power production and supply industries in 30 provinces of China. On the basis of considering the regional heterogeneity of the east, the middle and the west, this paper combines the metafrontier with the input distance function to construct the metafrontier input distance function, and uses the two-stage parametric linear programming method to estimate the distance function.

The structure of the rest of the paper is as follows. Section 2 introduces the metafrontier input distance function model we use to calculate the efficiency of the electricity, thermal power production and supply industries. Section 3 introduces the data in this paper. Section 4 is empirical results analysis. Section 5 summarizes the research conclusion and puts forward the policy suggestions.

\section{Methodology}

\subsection{The Metafrontier Input Distance Function}

We assume a production unit which produces good output and bad output. This production unit's inputs are $x_{t}^{g}=(l, k, e)$, outputs are $y_{t}^{g}=(q, u) . L, k$ and $e$ represent labor, capital and energy respectively. $q$ and $u$ denote good output and bad output respectively. In this paper, good output is defined as the total industrial output of the power, thermal power production and supply industry, while bad output is defined as the carbon dioxide emissions of the industry. Superscript $g$ and the subscript $t$ are group and time respectively. According to Shephard [3], the input distance function is:

$$
D_{t}^{g}\left(x_{t}^{g}, y_{t}^{g}\right)=\sup \left\{\theta \succ 0: \frac{x_{t}^{g}}{\theta} \in F_{t}^{g}\left(y_{t}^{g}\right)\right\}
$$

In the model (1), $F_{t}^{g}\left(y_{t}^{g}\right)$ represents the demand set of input factors. The boundary of the set is the technical boundary within the group (isoquant curve). This boundary represents the optimal or potential combination of inputs with existing technology and production capacity. The most efficient unit of production is at the boundary, where the input distance function is 1 . On the contrary, if the production unit is not on the technical boundary, it indicates that it is inefficient, and the existing input portfolio is not optimal, then the input distance function value is greater than 1. According to Färe and Grosskopf [42], the input distance function must satisfy the following constraints: First, the input distance function is concave, monotone nondecreasing and first order homogeneous about inputs. Second, regarding the good output as quasi-concave function, monotonically non-increasing, and regarding the bad output as monotonically non-decreasing. The monotonicity constraints above show that input and bad output are directly proportional to the value of the distance function and good output is inversely proportional to the value of the distance function. Under the same condition, the less input or bad output an enterprise uses or produces, the smaller the distance function value will be, and the higher the efficiency will be. The opposite is true of good output. 
Since the value of the input distance function $D_{t}^{g}\left(x_{t}^{g}, y_{t}^{g}\right)$ is the ratio between the actual input and potential input for the production unit, we can use the inverse of the input distance function to express the technical efficiency of the production unit according to Farrell [43]:

$$
0 \leq \frac{1}{D_{t}^{g}\left(x_{t}^{g}, y_{t}^{g}\right)}=T E_{t}^{g}\left(x_{t}^{g}, y_{t}^{g}\right) \leq 1
$$

As discussed above in the common boundary section, economic environment, regional differences, policy factors, etc., will cause each production unit within the technical boundary to form a group (for example, the east and west three groups in this paper), so a common boundary must be constructed to measure the production potential of each production unit. This technical boundary means the potential optimal portfolio of inputs that can be achieved when differences between each group converge. We define the input distance function of the common boundary as:

$$
D_{t}^{m}\left(x_{t}, y_{t}\right)=\sup \left\{\theta \succ 0: \frac{x_{t}}{\theta} \in F_{t}^{m}\left(y_{t}\right)\right\}
$$

$F_{t}^{m}\left(y_{t}\right)$ is the demand set of input factors based on common boundary. The boundary of the set is the common boundary. Common boundaries mean that production units have greater potential to reduce inputs than intra-group technical boundaries.

Similar to formula (2), the reciprocal of the input distance function value of the common boundary is used to express the technical efficiency based on the common boundary:

$$
0 \leq \frac{1}{D_{t}^{m}\left(x_{t}, y_{t}\right)}=T E_{t}^{m}\left(x_{t}, y_{t}\right) \leq 1
$$

By combining formula (2) and formula (4), we can calculate the technical gap $T G R_{t}$ :

$$
T G R_{t}=\frac{D_{t}^{g}\left(x_{t}^{g}, y_{t}^{g}\right)}{D_{t}^{m}\left(x_{t}, y_{t}\right)}=\frac{T E_{t}^{m}\left(x_{t}, y_{t}\right)}{T E_{t}^{g}\left(x_{t}^{g}, y_{t}^{g}\right)}
$$

\subsection{Parametric Linear Programming}

This section will introduce the method of estimating the metafrontier input distance function. Chen [37] used SFA method in the estimation of the technical boundary within the group while estimating the input distance function of the common boundary by linear programming method. The estimation method in this paper is different because the linear programming method is used in the two stages. In this way, the consistency of intra-group boundary estimation and common boundary estimation can be maintained. The following describes the method of two-stage parametric linear programming from three aspects: the selection of function form, the estimation of the inner boundary of a group, and the estimation of the common boundary. 


\subsubsection{Functional Form}

Parametric linear programming begins with selecting the appropriate functional form to simulate the technical boundary. According to Christensen et al. [44], Hailu and Veeman [5] applied the transcendental logarithm function to the estimation of input distance function, and the flexibility of this function can well simulate the technical boundary of input orientation. Taking the intra-group distance function as an example, the transcendental logarithm function is expressed as:

$$
\begin{aligned}
\ln D_{t}^{h g}\left(x_{t}^{g}, y_{t}^{g}, t\right)= & \alpha_{0}+\sum_{i} \alpha_{i} \ln x_{i, t}^{g}+\sum_{j} \beta_{j} \ln y_{j, t}^{g}+\chi t \\
& +\frac{1}{2} \sum_{i} \sum_{i^{\prime}} \varepsilon_{i i^{\prime}} \ln x_{i, t}^{g} \ln x_{i^{\prime}, t}^{g}+\frac{1}{2} \sum_{j} \sum_{j^{\prime}} \phi_{j j^{\prime}} \ln y_{j, t}^{g} \ln y_{j^{\prime}, t}^{g} \\
& +\frac{1}{2} \delta t^{2}+\sum_{i} \varphi_{i} \ln x_{i, t}^{g} t+\sum_{j} \gamma_{j} \ln y_{j, t}^{g} t+\sum_{i} \sum_{j} o_{i j} \ln x_{i, t}^{g} \ln y_{j, t}^{g}
\end{aligned}
$$

In formula (6), superscript $\mathrm{h}$ represents the number of research objects. The lowercase letter $\mathrm{g}$ indicates that the function corresponds to the inner group boundary. $i, i^{\prime}$ denotes inputs $(k, e, I) . j, j^{\prime}$ indicates outputs $(q, u) . \alpha_{0}, \alpha_{i}, \beta_{j}$ and so on are parameters to be estimated. The functional form of the common boundary is the same as that of Equation (6), which will not be repeated here.

\subsubsection{The Estimation of Intragroup}

Aigner and Chu [45] firstly used the method of linear programming for parameter estimation. Hailu and Veeman [5] used parametric linear programming to estimate the value of the input distance function. Parametric linear programming is very flexible, and it is convenient to apply various constraints on the distance function so as to better simulate the technical boundary of input guidance. Therefore, from this perspective, it is more suitable for estimating the input distance function than the econometric method. The parametric linear programming problem based on the inner boundary of the group is expressed as follows:

$$
\begin{aligned}
& \min \sum_{h}\left[\ln D_{t}^{h g}\left(x_{t}^{g}, y_{t}^{g}, t\right)-\ln 1\right] \\
& \text { s.t. }(1) \ln D_{t}^{g}\left(x_{t}^{g}, y_{t}^{g}, t\right) \geq 0, \\
& \text { (2) } \frac{\partial \ln D_{t}^{g}\left(x_{t}^{g}, y_{t}^{g}, t\right)}{\partial \ln q_{t}^{g}} \leq 0, \\
& \text { (3) } \frac{\partial \ln D_{t}^{g}\left(x_{t}^{g}, y_{t}^{g}, t\right)}{\partial \ln u_{t}^{g}} \geq 0, \\
& \text { (4) } \frac{\partial \ln D_{t}^{g}\left(x_{t}^{g}, y_{t}^{g}, t\right)}{\partial \ln x_{t}^{g}} \geq 0, \\
& \text { (5) } \sum_{i} \alpha_{i}=1, \\
& \text { (6) } \sum_{i} \varepsilon_{i i^{\prime}}=\sum_{i} o_{i j}=\sum_{i} \varphi_{i}=0, \\
& \text { (7) } \varepsilon_{i i^{\prime}}=\varepsilon_{i i^{\prime}}, \phi_{i j^{\prime}}=\phi_{j^{\prime} j}
\end{aligned}
$$


Formula (7) is essentially a goal minimization problem, that is, to make the actual input portfolio approach the potential input portfolio. Constraint condition (1) limits the value range of the input distance function. The value of the input distance function is greater than or equal to 1 , which indicates that the actual input has potential to reduce. (2), (3) and (4) indicate the monotonicity of the input distance function on good output, bad output and input. (5) and (6) constrain the homogeneity of the function with respect to input. (7) is a constraint on symmetry.

\subsubsection{The Estimation of Metafrontier}

Formula (7) shows the parametric linear programming of the inner boundary of the group. The estimation of the parametric linear programming of the common boundary is as follows:

$$
\begin{aligned}
& \min \sum_{h}\left[\ln D_{t}^{h m}\left(x_{t}^{m}, y_{t}^{m}, t\right)-\ln D_{t}^{g}\left(x_{t}^{g}, y_{t}^{g}, t\right)\right] \\
& \text { s.t. (1) } \ln D_{t}^{m}\left(x_{t}^{m}, y_{t}^{m}, t\right) \geq \ln D_{t}^{g}\left(x_{t}^{g}, y_{t}^{g}, t\right), \\
& \text { (2) } \frac{\partial \ln D_{t}^{m}\left(x_{t}^{m}, y_{t}^{m}, t\right)}{\partial \ln q_{t}^{m}} \leq 0, \\
& \text { (3) } \frac{\partial \ln D_{t}^{m}\left(x_{t}^{m}, y_{t}^{m}, t\right)}{\partial \ln u_{t}^{m}} \geq 0, \\
& \text { (4) } \frac{\partial \ln D_{t}^{m}\left(x_{t}^{m}, y_{t}^{m}, t\right)}{\partial \ln x_{t}^{m}} \geq 0, \\
& \text { (5) } \sum_{i} \alpha_{i}=1, \\
& \text { (6) } \sum_{i} \varepsilon_{i i^{\prime}}=\sum_{i} o_{i j}=\sum_{i} \varphi_{i}=0, \\
& \text { (7) } \varepsilon_{i i^{\prime}}=\varepsilon_{i^{\prime} i}, \phi_{j j^{\prime}}=\phi_{j^{\prime} j}
\end{aligned}
$$

It should be noted that the objective function and constraint condition (1) of the above formula are different from that of (7), because the common boundary must cover the inner boundary of the group and be as close as possible to it. The following figure illustrates this idea.

\section{Data}

The data used in this paper are the output and input data of 30 provinces (municipalities directly under the central government) of China (excluding Tibet) in power and thermal power production and supply industries from 2006 to 2015. The five-year plan is a feature of the Chinese government's management of the economy. The period from 2006 to 2015 covers two five-year plans of China's economic development, so the data selected in this paper can better reflect two complete economic cycles. Among them, output includes gross output value, carbon dioxide emissions. The inputs are capital, labor, and energy. The data were from China national statistical yearbook, China Emission Accounts and Datasets (CEADs). The total output value was converted into the actual output 
value by PPI on the basis of unchanged price in 2006, and the carbon dioxide emissions came from CEADs database. In terms of the calculation of capital stock, this paper, takes the average annual balance of the net fixed assets as the capital stock. Labor is the total number of annual employees in the power, heat and supply industries in each province. Energy input is expressed as standard coal (converted into standard coal in proportion to various energy sources). Descriptive statistics of all data are shown in Table 2.

As shown in the table below, the national data are grouped by east, middle and west. There are 14 provinces in the east, including Anhui, Beijing, Fujian, Guangdong, Hainan, Hebei, Heilongjiang, Jilin, Jiangsu, Liaoning, Shandong, Shanghai, Tianjin and Zhejiang. There are six central provinces, namely, Henan, Hunan, Hubei, Jiangxi, Inner Mongolia and Shanxi. There are 10 western provinces: Gansu, Guangxi, Guizhou, Ningxia, Qinghai, Shaanxi, Sichuan, Xinjiang, Yunnan and Chongqing. It can be seen from the table that the input-output of the three groups shows some differences. Among them, the average output value of the eastern power and thermal power production and supply industries is the highest, followed by the central region and the lowest in the western region. This is because the eastern regions are economically developed and densely populated, so the demand for electricity and heat is much higher than that in the central and western regions. At the same time, the eastern region has the most advanced productivity. We can see that the eastern region and the central region

Table 2. The description of data.

\begin{tabular}{|c|c|c|c|c|c|c|c|}
\hline Group & Variable & Unit & Observation & Mean & S.D. & Min & Max \\
\hline \multirow{5}{*}{ East } & $q$ & billion & 140 & 1113.79 & 815.90 & 65.79 & 3378.15 \\
\hline & $u$ & $10^{4}$ ton & 140 & $15,843.89$ & $10,957.44$ & 820.62 & 45,390 \\
\hline & $k$ & billion & 140 & 1113.25 & 727.95 & 102.58 & 3163.40 \\
\hline & $e$ & $\begin{array}{c}10^{4} \text { ton } \\
\text { Standard coal }\end{array}$ & 140 & 1749.75 & 1170.69 & 52.54 & 4182.77 \\
\hline & 1 & $10^{4}$ person & 140 & 9.55 & 5.71 & 1.17 & 23.24 \\
\hline \multirow{4}{*}{ Middle } & $q$ & billion & 60 & 740.97 & 380.20 & 361.57 & 1766.58 \\
\hline & $u$ & $10^{4}$ ton & 60 & $17,459.83$ & $10,212.42$ & 4620.67 & 42,009 \\
\hline & $k$ & billion & 60 & 1227.23 & 665.02 & 374.65 & 2574.73 \\
\hline & $e$ & $\begin{array}{c}10^{4} \text { ton } \\
\text { Standard coal }\end{array}$ & 60 & 1705.27 & 617.22 & 557.57 & 3089.09 \\
\hline \multirow{6}{*}{ West } & 1 & $10^{4}$ person & 60 & 11.11 & 3.80 & 5.14 & 20.62 \\
\hline & $q$ & billion & 100 & 341.15 & 181.05 & 91.12 & 690.14 \\
\hline & $u$ & $10^{4}$ ton & 100 & 7204.80 & 3674.29 & 970.76 & 21100 \\
\hline & $k$ & billion & 100 & 537.67 & 315.20 & 181.3 & 1408.91 \\
\hline & $e$ & $\begin{array}{c}10^{4} \text { ton } \\
\text { Standard coal }\end{array}$ & 100 & 836.37 & 385.99 & 72.09 & 1780.21 \\
\hline & 1 & $10^{4}$ person & 100 & 7.11 & 3.97 & 0.92 & 20.59 \\
\hline
\end{tabular}


do not have much difference in input, but the eastern region has a higher output value. The eastern and central regions use a lot of energy, so these two regions are the major $\mathrm{CO}_{2}$ emitters.

In order to prove the rationality of our grouping, we used the nonparametric $\mathrm{K}-\mathrm{W}$ rank sum test to test the results of mixed estimation according to the test method of Casu et al. (2013). The difference between mixed estimation and common boundary based estimation is that it assumes that there is no group difference among all production units. In this paper, the mixed estimation is to estimate all the data of 30 provinces with not considering the grouping. We applied the estimated results of this method to the K-W test, and the results shows that the $\mathrm{P}$ value is 0.0310 , so the null hypothesis is rejected at the significance level of $5 \%$, which indicated that it is very necessary for us to divide the national data into three groups, and the mixed estimation would produce deviation on the efficiency estimation.

\section{Empirical Analysis}

\subsection{The Estimation of Parameters}

In this section, we combine the data used with the common boundary distance function model to obtain the efficiency of electricity, thermal power production and supply industries in 30 provinces of China. We use GAMS software to estimate the transcendental logarithm function to obtain the values of each coefficient. In order to make the results converge, we standardized the data in the estimation. Table 3 shows the results of the coefficient estimation.

Table 3. The estimation of parameters for metafrontier input distance function.

\begin{tabular}{cccccc}
\hline Parameter & Variable & East & Middle & West & Metafrontier \\
\hline$\alpha_{0}$ & intercept & 0.1608 & 0.1515 & 0.4736 & 0.3601 \\
$\alpha_{k}$ & $\ln x_{k}$ & 0.8043 & 0.5444 & 0.6612 & 0.7042 \\
$\alpha_{e}$ & $\ln x_{e}$ & 0.1436 & 0.0556 & 0.3316 & 0.1951 \\
$\alpha_{l}$ & $\ln x_{l}$ & 0.0521 & 0.4000 & 0.0072 & 0.1007 \\
$\beta_{q}$ & $\ln y_{q}$ & -1.0033 & -1.2217 & -1.1694 & -0.9675 \\
$\beta_{u}$ & $\ln y_{u}$ & 0.0159 & 0.4840 & 0.2980 & 0.0226 \\
$\chi$ & $t$ & -0.0098 & -0.0195 & -0.0576 & -0.0130 \\
$\varepsilon_{k k}$ & $\ln x_{k} \cdot \ln x_{k}$ & -0.9093 & -1.2344 & -0.9353 & -0.5562 \\
$\varepsilon_{k e}$ & $\ln x_{k} \cdot \ln x_{e}$ & 0.0544 & 0.1392 & 0.5842 & 0.0853 \\
$\varepsilon_{k l}$ & $\ln x_{k} \cdot \ln x_{l}$ & 0.3861 & 0.2162 & 0.0332 & 0.1873 \\
$\varepsilon_{e k}$ & $\ln x_{e} \cdot \ln x_{k}$ & 0.0544 & 0.1392 & 0.5842 & 0.0853 \\
$\varepsilon_{e e}$ & $\ln x_{e} \cdot \ln x_{e}$ & 0.0057 & -0.0937 & -0.2855 & 0.0158 \\
$\varepsilon_{e l}$ & $\ln x_{e} \cdot \ln x_{l}$ & 0.0190 & 0.1936 & -0.0006 & 0.0193 \\
$\varepsilon_{l k}$ & $\ln x_{l} \cdot \ln x_{k}$ & 0.3861 & 0.2162 & 0.0332 & 0.1873 \\
$\varepsilon_{l e}$ & $\ln x_{l} \cdot \ln x_{e}$ & 0.0190 & 0.1936 & -0.0006 & 0.0193 \\
\hline & & & & \\
\hline & & & & \\
\hline
\end{tabular}


Continued

\begin{tabular}{|c|c|c|c|c|c|}
\hline$\varepsilon_{l l}$ & $\ln x_{l} \cdot \ln x_{l}$ & -0.0154 & 0.2301 & -0.0130 & -0.0435 \\
\hline$\phi_{q q}$ & $\ln y_{q} \cdot \ln y_{q}$ & -0.0702 & 0.8191 & -0.1761 & -0.1154 \\
\hline$\phi_{q u}$ & $\ln y_{q} \cdot \ln y_{u}$ & 0.0009 & 0.9495 & 0.3815 & 0.0422 \\
\hline$\phi_{u q}$ & $\ln y_{u} \cdot \ln y_{q}$ & 0.0009 & 0.9495 & 0.3815 & 0.0422 \\
\hline$\phi_{u u}$ & $\ln y_{u} \cdot \ln y_{u}$ & 0.0119 & -0.0306 & -0.2640 & 0.0006 \\
\hline$\delta$ & $t^{2}$ & 0.0014 & 0.0015 & 0.0057 & 0.0022 \\
\hline$\varphi_{k}$ & $\ln x_{k} \cdot t$ & 0.0112 & 0.0105 & 0.0059 & 0.0121 \\
\hline$\varphi_{e}$ & $\ln x_{e} \cdot t$ & -0.0113 & 0.0077 & -0.0061 & -0.0148 \\
\hline$\varphi_{l}$ & $\ln x_{l} \cdot t$ & 0.0001 & -0.0182 & 0.0002 & 0.0027 \\
\hline$\gamma_{q}$ & $\ln y_{q} \cdot t$ & -0.0014 & -0.0019 & 0.0393 & -0.0041 \\
\hline$\gamma_{u}$ & $\ln y_{u} \cdot t$ & 0.0008 & -0.0312 & -0.0148 & 0.0039 \\
\hline$o_{k q}$ & $\ln x_{k} \cdot \ln y_{q}$ & 0.4544 & 0.8529 & 0.5347 & 0.3511 \\
\hline$o_{k u}$ & $\ln x_{k} \cdot \ln y_{u}$ & 0.0175 & -0.4130 & -0.5123 & -0.0259 \\
\hline$o_{e q}$ & $\ln x_{e} \cdot \ln y_{q}$ & -0.0259 & -0.2603 & -0.1804 & -0.0944 \\
\hline$o_{e u}$ & $\ln x_{e} \cdot \ln y_{u}$ & -0.0486 & 0.0930 & 0.1746 & -0.0304 \\
\hline$o_{l q}$ & $\ln x_{l} \cdot \ln y_{q}$ & -0.3917 & -0.2868 & -0.0154 & -0.2226 \\
\hline$o_{l u}$ & $\ln x_{l} \cdot \ln y_{u}$ & -0.0056 & 0.0142 & -0.0012 & 0.0222 \\
\hline
\end{tabular}

\subsection{The Efficiency Analysis of Electricity, Thermal Power Production and Supply Industry}

\subsubsection{Description of Various Efficiency Indicators in the East, Middle and West}

Table 4 shows the technical efficiency and technical gap between the electricity, thermal power production and supply industries in the east, middle and west. In the Table 4, PTE is the efficiency value calculated by using mixed estimation, and the results are listed for the purpose of comparing with the result of metafrontier estimation. TE stands for technical efficiency based on intra group boundaries. MTE is the result of metafrontier estimation. TGR is the quotient between MTE and TE, indicating the technical gap. Table 4 is described in three aspects below.

Firstly, by comparing PTE and MTE, we can find that the mixed estimation overestimates the efficiency value of the eastern, middle and western regions. Specifically, under the mixed estimation, the average efficiency of east, middle and west are $0.8660,0.6068$ and 0.6329 respectively. The technical efficiency ratio based on common boundary is $0.8559,0.5956$ and 0.5864 . The $\mathrm{K}-\mathrm{W}$ test in this paper has showed there are significant differences in three regions, so the three regions each have their own technological frontier. This paper constructs the common boundary (metafrontier) is a potential technology frontier (as shown in Figure 2), and mixed estimation is not a suitable method, so it cannot accurately simulate potential technical boundaries which all province face. Just like Huang et al. (2010), mixed estimation will produce biased efficiency estimation. 
Table 4. Estimation of efficiency.

\begin{tabular}{|c|c|c|c|}
\hline Item & Group & Statistic & Value \\
\hline \multirow[t]{6}{*}{$\mathrm{TE}$} & east & mean & 0.8785 \\
\hline & & s.d. & 0.1322 \\
\hline & middle & mean & 0.8855 \\
\hline & & s.d. & 0.1258 \\
\hline & west & mean & 0.8115 \\
\hline & & s.d. & 0.1492 \\
\hline \multirow[t]{6}{*}{ MTE } & east & mean & 0.8559 \\
\hline & & s.d. & 0.1238 \\
\hline & middle & mean & 0.5956 \\
\hline & & s.d. & 0.1607 \\
\hline & west & mean & 0.5864 \\
\hline & & s.d. & 0.1237 \\
\hline \multirow[t]{6}{*}{ TGR } & east & mean & 0.9757 \\
\hline & & s.d. & 0.0223 \\
\hline & middle & mean & 0.6709 \\
\hline & & s.d. & 0.1433 \\
\hline & west & mean & 0.7268 \\
\hline & & s.d. & 0.1005 \\
\hline \multirow[t]{6}{*}{ PTE } & east & mean & 0.8660 \\
\hline & & s.d. & 0.1310 \\
\hline & middle & mean & 0.6068 \\
\hline & & s.d. & 0.1871 \\
\hline & west & mean & 0.6329 \\
\hline & & s.d. & 0.1359 \\
\hline
\end{tabular}

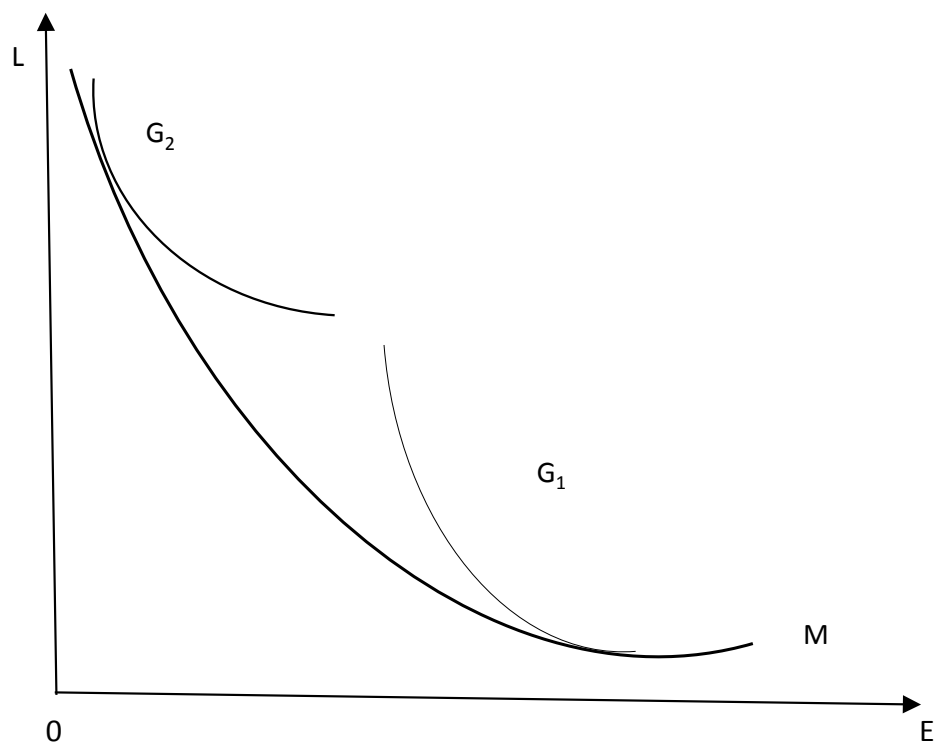

Figure 2. The illustration of metafrontier. 
Secondly, in terms of TE, the performance of the east and the middle is not different, but the efficiency value in the west is significantly lower than that in the east and the middle. Such results cannot indicate which of the east, west and east regions performs better in efficiency, because the TE value is only compared within each region. Only the value of MTE can truly reflect the efficiency difference between east, middle and west, because they are all compared based on a common boundary (metafrontier) at this time. Table 4 shows that the MTE value in the east is much higher than that in the Middle and west, while that in the middle is slightly higher than that in the west. This indicates that the eastern region is significantly more efficient if the common potential technology boundary is used as the benchmark. Because the economic and technological level of the east is stronger than that of the central and western regions, the eastern region as a whole is closer to the potential technological boundary. It also means that for the same amount of output, the east can do it with less input. The difference in MTE between the east and the middle can also explain why the input used is similar but the output value in the east is higher (Table 2).

Finally, we analyze the technical gap (TGR). TGR reflects the gap between intra group frontier and metafrontier. Clearly, the TGR performance in the east is much better than that in the middle and west. It shows again that the input portfolio of eastern power, thermal power production and supply industries is closer to the potential optimal input portfolio. In addition, TGR is 0.6709 in the middle and 0.7268 in the west. The reason why the middle part is smaller than the west part is that TGR is the quotient of MTE and TE. Although the TE in the middle part is higher than that in the west part, the MTE of the two is not much different, which ultimately makes the TGR in the west higher than that in the middle part.

On the whole, in the electricity, thermal power production and supply industries, the efficiency performance of the eastern region is better than that of the central and western regions, showing an unbalanced state of development. The central and western regions need to improve technology, further optimize the investment mix, and get rid of the extensive development mode.

\subsubsection{The Trending Analysis of Efficiency for 30 Provinces}

Next, we will analyze the annual change trend of TE, MTE and TGR in the eastern, central and western regions. Figures 3-5 respectively show the trend change charts of the three indicators during the "eleventh five-year plan" and "twelfth five-year plan".

In Figure 3, ETE, MTE and WTE respectively represent the efficiency indexes of the three regions (Figure 4 and Figure 5 are the same with them). Since they are all intra-group technical boundaries, they are not comparable. Here, we only analyze the change trend of each region. First of all, the overall trend of technical efficiency in eastern region from 2006 to 2015 is relatively stable with little change. Of these, only a small rise followed by a fall was recorded between 2011 and 2013. Overall, the technical efficiency of the eastern region increased slightly, 




Figure 3. The trending of efficiency based on intragroup frontier.

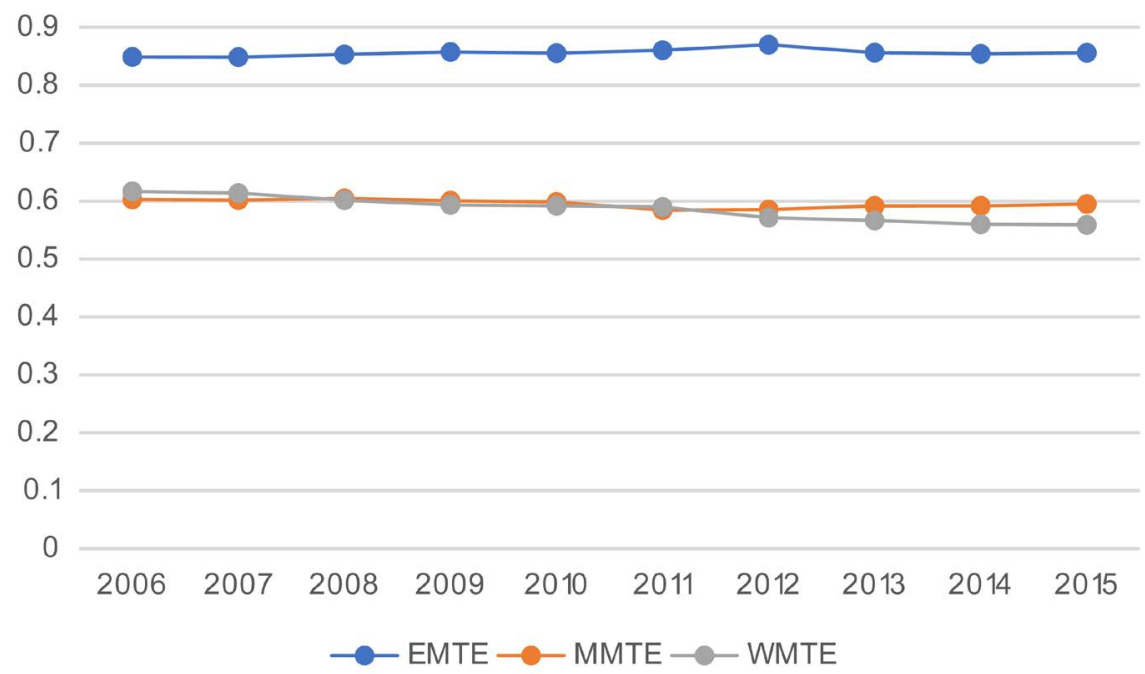

Figure 4. The trending of efficiency based on metafrontier.

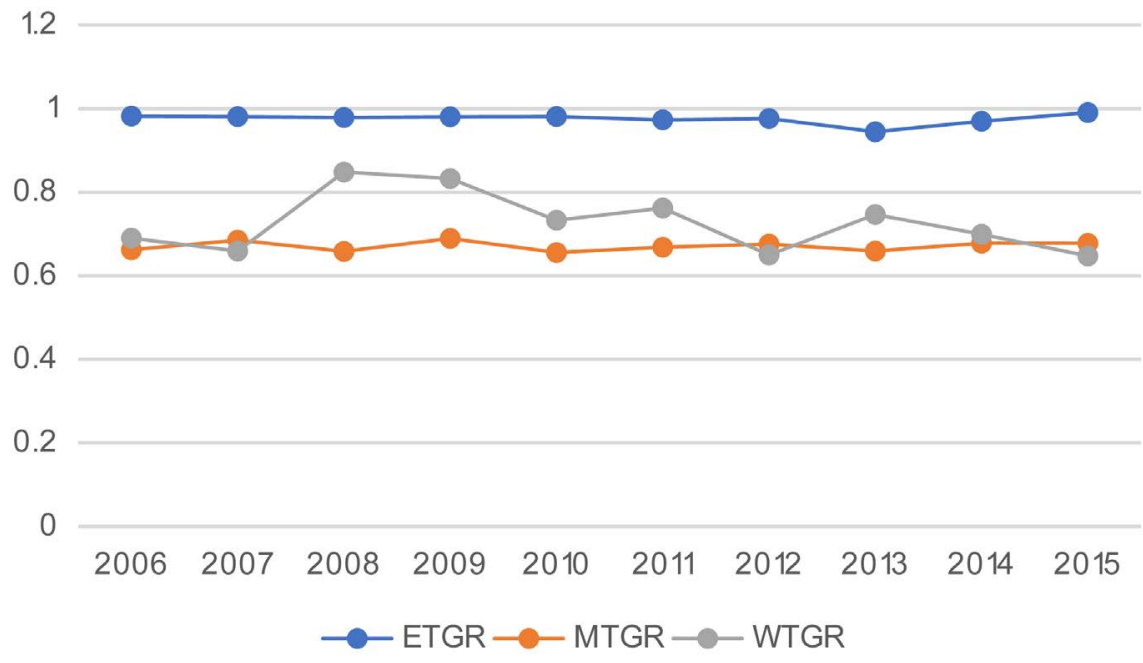

Figure 5. The trending of technological efficiency gap. 
and gradually leveled off from 2013 to 2015. Secondly, the technical efficiency of the electricity, thermal power production and supply industry in the central region shows a trend of decreasing at first and then increasing, with a large range of change. With 2011 as the turning point, it was on a downward trend before and then on an upward trend. Finally, the efficiency performance of the western region was relatively stable before 2012, during which there were rises and falls, but the range was small, and then it showed an obvious upward trend until 2015. To sum up, the technical efficiency of the eastern region showed a stable trend during the "eleventh five-year plan" and "twelfth five-year plan", with an overall slight increase. The technical efficiency within the group in the central and western regions showed obvious differences during the "eleventh five-year plan" and "twelfth five-year plan". This paper believes that the rising of the two in the "twelfth five-year plan" is mainly due to the gradual slowing of China's economic growth during this period, which has entered the new normal, and the country pays more attention to the development of economic quality. These changes will force the electricity, thermal power production and supply industries to improve technology and efficiency in the production process.

We use Figure 3 and Figure 4 to compare the efficiency performance of east and west based on metafrontier. From the two figures, it is clear that the electricity, thermal power production and supply industries in the east is more technically efficient than that in the middle and west based on metafrontier. Moreover, the central and western regions did not show a catch-up trend during the 11th and 12th five-year plans. This situation shows that the east, the central and western regions appear unbalanced state of development. The east as a whole is closer to the common boundary (metafrontier), representing the most advanced level of development in China's electricity, thermal power production and supply industries. However, there is still a big gap between three regions. Although their intra-group technical efficiency has been greatly improved during the "twelfth five-year plan" period, their actual input portfolio is still far from the potential optimal input portfolio, and there is no substantial progress during the whole "eleventh five-year plan" and "twelfth five-year plan" period. Therefore, the electricity, thermal power production and supply industries in the central and western regions still have much room for improvement in optimizing the investment mix.

\section{Summary and Conclusion}

In this paper, the metafrontier input distance function of two-stage linear programming is constructed and used to evaluate the efficiency performance of China's electricity, thermal power production and supply industries during the 11 th and 12th five-year plans. The results show that there are significant differences between eastern, middle and western regions, which indicates that the grouping method of metafrontier in this paper is scientific. From the efficiency performance of the three regions, the efficiency value in the east is higher than 
that in the middle and west, that is, the east is closer to the potential production boundary. During the 11th and 12th five-year plans, the gap between the central, western regions and the eastern regions did not shrink. Therefore, we can think that the development of China's power, thermal power production and supply industry is unbalanced. In the future, the state should actively change the development mode of electricity, thermal power production and supply industries in the central and western regions, and take a series of measures to improve the level of technology and productivity in the central and western regions.

This paper mainly analyzes the efficiency performance of electricity, thermal power production and supply industries. Efficiency analysis is only a static analysis, so it can further analyze the change of dynamic productivity in the industry in the future. In addition, due to the linear programming method used in this paper, the estimation results lack relevant statistics. In future research, bootstrap method can be used to solve this problem.

\section{Conflicts of Interest}

The author declares no conflicts of interest regarding the publication of this paper.

\section{References}

[1] Lee, M. and Zhang, N. (2012) Technical Efficiency, Shadow Price of Carbon Dioxide Emissions, and Substitutability for Energy in the Chinese Manufacturing Industries. Energy Economics, 34, 1492-1497. https://doi.org/10.1016/j.eneco.2012.06.023

[2] Shephard, R.W. (1953) Cost and Production Function. Princeton University Press, Princeton.

[3] Shephard, R.W. (1970) Theory of Cost and Production Function. Princeton University Press, Princeton.

[4] Färe, R. and Primont, D. (1995) Multi-Output Production and Duality: Theory and Application. Kluwer Academic Publishers, Boston.

https://doi.org/10.1007/978-94-011-0651-1

[5] Hailu, A. and Veeman, T.S. (2000) Environmentally Sensitive Productivity Analysis of the Canadian Pulp and Paper Industry, 1959-1994: An Input Distance Function Approach. Journal of Environmental Economics \& Management, 40, 251-274. https://doi.org/10.1006/jeem.2000.1124

[6] Lee, M. (2005) The Shadow Price of Substitutable Sulfur in the US Electric Power Plant: A Distance Function Approach. Journal of Environmental Management, 77, 104-110. https://doi.org/10.1016/j.jenvman.2005.02.013

[7] Zhou, P., Ang, B.W. and Zhou, D.Q. (2012) Measuring Economy-Wide Energy Efficiency Performance: A Parametric Frontier Approach. Applied Energy, 90, 196-200. https://doi.org/10.1016/j.apenergy.2011.02.025

[8] Das, A. and Kumbhakar, S.C. (2012) Productivity and Efficiency Dynamics in Indian Banking: An Input Distance Function Approach Incorporating Quality of Inputs and Outputs. Journal of Applied Econometrics, 27, 205-234. https://doi.org/10.1002/jae.1183

[9] Das, A. and Kumbhakar, S.C. (2016) Markup and Efficiency of Indian Banks: An 
Input Distance Function Approach. Empirical Economics, 51, 1689-1719 https://doi.org/10.1007/s00181-015-1062-4

[10] Ma, C.B. and Hailu, A. (2016) The Marginal Abatement Cost of Carbon Emissions in China. The Energy Journal, 37, 111-127. https://doi.org/10.5547/01956574.37.si1.cma

[11] Färe, R., Grosskopf, S., Lovell, C.A.K. and Pasurka, C.A. (1989) Multilateral Productivity Comparison when Some Outputs Are Undesirable: A Nonparametric Approach. Review of Economics and Statistics, 71, 90-98. https://doi.org/10.2307/1928055

[12] Färe, R., Grosskopf, S., Lovell, C.A.K. and Yaisawarng, S. (1993) Derivation of Shadow Prices for Undesirable Outputs: A Distance Function Approach. Review of Economics and Statistics, 75, 374-380. https://doi.org/10.2307/2109448

[13] Coggins, J.S. and Swinton J.R. (1996) The Price of Pollution: A Dual Approach to Valuing $\mathrm{SO}_{2}$ Allowances. Journal of Environmental Economics and Management, 30, 58-72. https://doi.org/10.1006/jeem.1996.0005

[14] Swinton, J.R. (1998) At What Cost Do We Reduce Pollution? Shadow Prices of $\mathrm{SO}_{2}$ Reduction. The Energy Journal, 19, 63-83. https://doi.org/10.5547/issn0195-6574-ej-vol19-no4-3

[15] Swinton, J.R. (2002) The Potential for Cost Savings in the Sulfur Dioxide Allowance Market: Empirical Evidence from Florida. Land Economics, 78, 390-404. https://doi.org/10.2307/3146897

[16] Newman, C. and Matthews, A. (2006) The Productivity Performance of Irish Dairy Farms 1984-2000: A Multiple Output Distance Function Approach. Journal of Productivity Analysis, 26, 191-205. https://doi.org/10.1007/s11123-006-0013-7

[17] Newman, C. and Matthews, A. (2007) Evaluating the Productivity Performance of Agricultural Enterprises in Ireland Using a Multiple Output Distance Function Approach. Journal of Agricultural Economics, 58, 128-151. https://doi.org/10.1111/j.1477-9552.2007.00084.X

[18] Feng, G. and Serletis, A. (2010) Efficiency, Technical Change, and Returns to Scale in Large US Banks: Panel Data Evidence from an Output Distance Function Satisfying Theoretical Regularity. Journal of Banking \& Finance, 34, 127-138. https://doi.org/10.1016/j.jbankfin.2009.07.009

[19] Areal, F.J., Tiffin, R. and Balcombe, K.G. (2012) Provision of Environmental Output within a Multi-Output Distance Function Approach. Ecological Economics, 78, 47-54. https://doi.org/10.1016/j.ecolecon.2012.03.011

[20] Assaf, A.G. and Agbola, F.W. (2012) Efficiency Analysis of the Australian Accommodation Industry: A Bayesian Output Distance Function. Journal of Hospitality \& Tourism Research, 38, 116-132. https://doi.org/10.1177/1096348012451459

[21] Chung, Y.H., Färe, R. and Grosskopf, S. (1997) Productivity and Undesirable Outputs: A Directional Distance Function Approach. Journal of Environmental Management, 51, 229-240. https://doi.org/10.1006/jema.1997.0146

[22] Färe, R., Grosskopf, S., Noh, D.W. and Weber, W. (2005) Characteristics of a Polluting Technology: Theory and Practice. Journal of Econometrics, 126, 469-492. https://doi.org/10.1016/j.jeconom.2004.05.010

[23] Mcmullen, B.S. and Noh, D.W. (2007) Accounting for Emissions in the Measurement of Transit Agency Efficiency: A Directional Distance Function Approach. Transportation Research, Part D: Transport and Environment, 12, 1-9. https://doi.org/10.1016/j.trd.2006.10.001 
[24] Watanabe, M. and Tanaka, K. (2007) Efficiency Analysis of Chinese Industry: A Directional Distance Function Approach. Energy Policy, 35, 6323-6331. https://doi.org/10.1016/j.enpol.2007.07.013

[25] Murty, M.N., Kumar, S. and Dhavala, K.K. (2007) Measuring Environmental Efficiency of Industry: A Case Study of Thermal Power Generation in India. Environmental and Resource Economics, 38, 31-50. https://doi.org/10.1007/s10640-006-9055-6

[26] Macpherson, A.J., Principe, P.P. and Smith, E.R. (2010) A Directional Distance Function Approach to Regional Environmental-Economic Assessments. Ecological Economics, 69, 1918-1925. https://doi.org/10.1016/j.ecolecon.2010.04.012

[27] Yuan, P., Cheng, S., Sun, J. and Liang, W.B. (2013) Measuring the Environmental Efficiency of the Chinese Industrial Sector: A Directional Distance Function Approach. Mathematical and Computer Modelling, 58, 936-947. https://doi.org/10.1016/j.mcm.2012.10.024

[28] Wang, H., Zhou, P. and Zhou, D.Q. (2013) Scenario-Based Energy Efficiency and Productivity in China: A Non-Radial Directional Distance Function Analysis. Energy Economics, 40, 795-803. https://doi.org/10.1016/j.eneco.2013.09.030

[29] Xie, H., Shen, M. and Wei, C. (2016) Technical Efficiency, Shadow Price and Substitutability of Chinese Industrial $\mathrm{SO}_{2}$ Emissions: A Parametric Approach. Journal of Cleaner Production, 112, 1386-1394. https://doi.org/10.1016/j.jclepro.2015.04.122

[30] Hayami, Y. (1969) Sources of Agricultural Productivity Gap among Selected Countries. American Journal of Agricultural Economics, 51, 564-575. https://doi.org/10.2307/1237909

[31] Hayami, Y. and Ruttan, V.W. (1970) Agricultural Productivity Differences among Countries. American Economic Review, 60, 895-911.

[32] Battese, G.E. and Rao, D.S.P. (2002) Technology Gap, Efficiency, and a Stochastic Metafrontier Function. International Journal of Business and Economics, 1, 87-93.

[33] Rao, D.S.P., O’Donnell, J.C. and Battese, G.E. (2003) Metafrontier Functions for the study of Inter-Regional Productivity Differences. Center for Efficiency and Productivity Analysis, Working Paper.

[34] Battese, G.E., Rao, D.S.P. and O'Donnell, J.C. (2004) A Metafrontier Production Function for Estimation of Technical Efficiencies and Technology Gaps for Firms Operating under Different Technologies. Journal of Productivity Analysis, 21, 91-103. https://doi.org/10.1023/b:prod.0000012454.06094.29

[35] O’Donnell, Rao, D.S.P., J.C. and Battese, G.E. (2008) Metafrontier Frameworks for the Study of Firm-Level Efficiencies and Technology Ratios. Empirical Economics, 34, 231-255. https://doi.org/10.1007/s00181-007-0119-4

[36] Huang, Y.J., Chen, K.H. and Yang, C.H. (2010) Cost Efficiency and Optimal Scale of Electricity Distribution Firms in Taiwan: An Application of Metafrontier Analysis. Energy Economics, 32, 15-23. https://doi.org/10.1016/j.eneco.2009.03.005

[37] Chen, K.H. (2012) Incorporating Risk Input into the Analysis of Bank Productivity: Application to the Taiwanese Banking Industry. Journal of Banking \& Finance, 36, 1911-1927. https://doi.org/10.1016/j.jbankfin.2012.02.012

[38] Huang, C.J., Huang, T.H. and Liu, N.H. (2014) A New Approach to Estimating the Metafrontier Production Function Based on a Stochastic Frontier Framework. Journal of Productivity Analysis, 42, 241-254. https://doi.org/10.1007/s11123-014-0402-2

[39] Huang, T.H., Chiang, D.L. and Tsai, C.M. (2015) Applying the New Metafrontier 
Directional Distance Function to Compare Banking Efficiencies in Central and Eastern European Countries. Economic Modelling, 44, 188-199. https://doi.org/10.1016/j.econmod.2014.10.029

[40] Zhang, N. and Wang, B. (2015) A Deterministic Parametric Metafrontier Luenberger Indicator for Measuring Environmentally-Sensitive Productivity Growth: A Korean Fossil-Fuel Power Case. Energy Economics, 51, 88-98.

https://doi.org/10.1016/j.eneco.2015.06.003

[41] Du, L.M., Hanley, A. and Zhang, N. (2016) Environmental Technical Efficiency, Technology Gap and Shadow Price of Coal-Fuelled Power Plants in China: A Parametric Meta-Frontier Analysis. Resource and Energy Economics, 43, 14-32. https://doi.org/10.1016/j.reseneeco.2015.11.001

[42] Färe, R. and Grosskopf, S. (1990) A Distance Function Approach to Price Efficiency. Journal of Public Economics, 43, 123-126.

https://doi.org/10.1016/0047-2727(90)90054-1

[43] Farrell, M.J. (1957) The Measurement of Productive Efficiency. Journal of the Royal Statistical Society, 120, 253-281.

[44] Christensen, L.R. and Lau, J.L.J. (1973) Transcendental Logarithmic Production Frontiers. The Review of Economics and Statistics, 55, 28-45.

[45] Aigner, D.J. and Chu, S.F. (1968) On Estimating the Industry Production Function. American Economic Review, 58, 826-839. 